\title{
CERTIFICAÇÃO E VALIDAÇÃO DA APRENDIZAGEM NA EDUCAÇÃO DE JOVENS E ADULTOS: a experiência dos NEEJAs em Porto Alegre
}

\author{
Simone Valdete dos Santos \\ Universidade Federal do Rio Grande do Sul - UFRGS
}

\begin{abstract}
Resumo
A certificação da escolaridade resulta em certificação e validação da aprendizagem, embora esses termos não sejam sinônimos. Tais processos pedagógicos são fundamentais para jovens e adultos trabalhadores acessarem possibilidades de emprego e darem continuidade a seus estudos. Os Núcleos Estaduais de Educação de Jovens e Adultos (NEEJAs) no Rio Grande do Sul aplicam provas para validar os níveis de ensino. A metodologia da pesquisa de caráter qualitativo correspondeu a visitas para observações e entrevistas com gestores e professores de cinco NEEJAs, localizados em Porto Alegre, sendo os dados sistematizados em conformidade à análise de conteúdo. Os resultados indicam a flexibilidade dos horários de atendimento, o conteúdo apresentado em material didático específico, as provas fracionadas, a ausência de ambientes digitais e a desvinculação com os saberes advindos das experiências de trabalho dos estudantes, distanciandose da defesa de que os NEEJAs são importantes à oferta de alternativas. Os NEEJAs confirmam a relevância da oferta de alternativas para o reconhecimento e a validação da aprendizagem de jovens e adultos trabalhadores.
\end{abstract}

Palavras-chave: reconhecimento e validação da aprendizagem; educação de jovens e adultos; núcleos estaduais de educação de jovens e adultos.

\begin{abstract}
Schooling certification results in learning recognition and validation, although these terms are not synonymous. These pedagogical processes are fundamental for young and working adults in accessing job opportunities and continuing their studies. The State Centers for Youth and Adult Education (NEEJAs) in Rio Grande do Sul apply tests to validate levels of education of youth and adults. Qualitative research methodology was used in visits for observing and interviewing managers and teachers of five NEEJAs located in Porto Alegre, and the data were systematized according to content analysis. Results have shown schools offer flexible schedules for students, content is presented in specific didactic material and partial tests are applied. The absence of digital environments and the disconnection with the knowledge from the students' work experiences was also observed. The NEEJAs attest the relevance of providing alternatives for learning recognition and validation for young and working adults.
\end{abstract}

Keywords: learning recognition and validation; youth and adult education; state centers for youth and adult education. 


\section{Introdução}

A certificação de escolaridade, o reconhecimento de saberes e o aproveitamento de estudos ${ }^{1}$ compõem processos educativos de ensino e aprendizagem essenciais para que jovens e adultos constituam espaços dentro do sistema escolar a fim de que acessem seu direito à Educação e recuperem o tempo perdido em uma escola inserida em uma lógica de que "qualquer ensinamento serve" para as classes subalternas².

Conforme a obra de Georges Balandier (1997), é possível compreender a inserção de estudantes da modalidade Educação de Jovens e Adultos na categoria de figuras de desordem, na consideração da então ordem escolar instituída na Educação Básica, a qual prioriza as crianças e os jovens na denominada "idade regular".

A mudança na Lei de Diretrizes e Bases 9394/96 pela Lei Federal 13.632 de 2018, em seu artigo 37 define que "A educação de jovens e adultos será destinada àqueles que não tiveram acesso ou continuidade de estudos nos ensinos fundamental e médio na idade própria e constituirá instrumento para a educação e a aprendizagem ao longo da vida” e refuta a ideia de que exista uma "idade regular" para aprender, pois a aprendizagem ocorre ao longo de toda a vida.

Por outro lado, a Emenda Constitucional 95 de 2016, que institui o congelamento de investimentos públicos até 2036 em saúde e educação, e a Reforma do Ensino Médio, instituída pela Lei 13415 de 2017, em cujo texto está ausente a oferta do Ensino Médio no período noturno, consistem em prerrogativas legais as quais ameaçam a melhoria e até mesmo a continuidade de classes de escolarização de jovens e adultos pelas redes de ensino municipais, estaduais e federal, bem como a existência de práticas pedagógicas de validação e certificação de escolaridade públicas como os Núcleos de Educação de Jovens e Adultos (NEEJAs) do Rio Grande do Sul, objeto da pesquisa empírica realizada.

Os Núcleos Estaduais de Educação de Jovens e Adultos (NEEJAs) do Rio Grande do Sul aplicam as provas para a concessão da certificação da escolarização básica para pessoas de 18 anos ou mais, em conformidade com a resolução 343/2018, aprovada pelo Conselho Estadual de Educação (CEED/RS), que também determina a presença no turno noturno de estudantes de 18 anos e mais, enfrentando o fenômeno da juvenilização ${ }^{3}$ da EJA, resultado do ingresso de estudantes de 15 anos completos na EJA Fundamental, desde a aprovação da Lei de Diretrizes e Bases da Educação Nacional - LDB 9394/1996. O processo de certificação realizado pelos NEEJAs também cumpre a Emenda Constitucional 59, aprovada em 2009 e que determina a obrigatoriedade da Educação Básica dos 06 aos 17 anos, ou seja, os jovens têm o direito de frequentar a escola regular até os 17 anos, mesmo em situação de reprovação ou descontinuidade dos estudos.

O presente artigo, em um primeiro momento, apresenta contrapontos sobre a legislação que respalda a certificação dos níveis de escolaridade e apresenta um levantamento de caráter exploratório realizado junto aos sites institucionais das Secretarias Estaduais de Educação, verificando os programas existentes vinculados aos exames de certificação. Há também registros presentes no mesmo sentido junto ao site dos Fóruns EJAs do Brasil. 
A seguir, apresenta os NEEJAs por meio de pesquisa realizada em cinco núcleos localizados em Porto Alegre; a legislação que embasa os processos de certificação de escolaridade e/ ou certificação da aprendizagem; e os programas que articulam elevação de escolaridade e qualificação profissional, a exemplo do Programa Rede Nacional de Certificação Profissional e Formação Inicial e Continuada (Rede CERTIFIC), instituído pela portaria interministerial $\mathrm{N}^{0} 1.082$ de 20/11/2009, do então existente e ativo Ministério do Trabalho e Emprego ${ }^{4}$ e do Ministério da Educação. Para qualquer certificação profissional, o Ensino Fundamental completo é pressuposto mínimo para o CERTIFIC, sendo a rede federal de Educação Profissional e Tecnológica a responsável pela organização dessa política pública.

Na sequência, o artigo apresenta um panorama nacional e internacional sobre reconhecimento dos saberes do trabalho, finalizando com as alternativas possíveis, as quais realizam ou intencionam realizar a certificação de aprendizagens de forma geral, vinculada aos saberes curriculares e às possibilidades de certificação laboral, considerando que no Brasil o conhecimento pela prática do trabalho é inerente às classes subalternas, uma vez que o acesso à escola lhes é historicamente negado.

Diante de tal realidade, a oferta da Educação de Jovens e Adultos (EJA), na modalidade Educação a Distância, de certa forma se relaciona com os processos educativos de certificação, nos quais os estudantes podem se deslocar para os estabelecimentos de ensino somente para realizar a prova. Esse cenário acompanha um discurso e uma prática institucional de diminuição das matrículas da EJA presencial e cortes do orçamento, inviabilizando o cumprimento das metas 8, 9 e 10 do Plano Nacional de Educação - Lei 13.005/2014, que objetivam, respectivamente, a elevação da escolaridade; a alfabetização de jovens e adultos; e a EJA integrada, sendo a meta 10 articulada à Educação Profissional.

Em um momento de arrefecimento dos direitos sociais e de extinção do Ministério do Trabalho e Emprego, a análise das práticas pedagógicas dos NEEJAs do Rio Grande do Sul valoriza a existência destas alternativas de inspiração nos antigos supletivos ${ }^{5}$, mas com demanda na incompletude da Educação Básica pela população, quem sabe rompendo com a afirmação de Darcy Ribeiro na palestra intitulada Sobre o Óbvio, no ano de 1977, em um Congresso da Sociedade Brasileira para o Progresso da Ciência (SBPC): “A Crise da Educação no Brasil não é uma Crise, é um Projeto".

\section{Contextos da existência dos NEEJAs}

A certificação é uma das alternativas procuradas pelos estudantes para a conclusão rápida dos níveis da escolarização. A partir de 2017 não contamos mais com o Exame Nacional do Ensino Médio (ENEM) para a certificação da conclusão dessa etapa da Educação Básica.

A política nacional de avaliação e exames da Educação Básica é regulamentada pelo Decreto Presidencial 9.432 de 2018 institui o Exame Nacional para Certificação de 
Competências para Jovens e Adultos (ENCCEJA), que determina em seu artigo $6^{\circ}$, parágrafo único: “O ENCCEJA poderá ser utilizado para fins de certificação de níveis de ensino”.

O ENCCEJA, que vinha em um processo de implementação pelo Instituto Nacional de Estudos e Pesquisas Educacionais Anísio Teixeira (INEP) desde 2002 6 , mesmo que com interrupções em sua aplicação, passa a compor de forma absoluta a certificação nacional dos níveis da Educação Básica a partir de 2017, estabelecido ao ENEM apenas o acesso ao ensino superior e a avaliação da Educação Básica, sem concessão de certificação, conforme o artigo $7^{\circ}$ do Decreto 9432/2018: "O ENEM tem como objetivo aferir o domínio das competências e das habilidades esperadas ao final da educação básica”; e, em seu parágrafo único, que "O ENEM poderá ser utilizado como mecanismo de acesso à educação superior e aos programas governamentais de financiamento ou apoio ao estudante do ensino superior”.

Durante o ano de 2017, a fim de realizar um estudo exploratório de verificação da existência de propostas pedagógicas semelhantes aos NEEJAs do Rio Grande do Sul, foram pesquisados $^{7}$ os sites institucionais das 27 secretarias estaduais de educação do Brasil e o resultado foi que nenhum outro serviço foi encontrado com essa nomenclatura. A proposta mais similar foi a dos Centros de Educação de Jovens e Adultos (CEJA's), que ofertam ensino não-presencial, com a possibilidade de encontros para orientação relacionadas aos exames para certificação. As secretarias estaduais de educação que apresentam os CEJA's em seus sites são: Alagoas, Ceará, Espírito Santo, Maranhão, Mato Grosso, Rio de Janeiro, Santa Catarina e São Paulo.

No site da Secretaria de Estado de Educação do Rio de Janeiro, encontramos informações sobre o funcionamento e os objetivos do CEJA, já nos sites das demais secretarias estaduais, foram encontradas apenas menções à sigla, sem nenhum tipo de esclarecimento ou informação.

A Prefeitura da Cidade do Rio de Janeiro tem como oferta o Centro Municipal de Referência de Educação de Jovens e Adultos (CREJA), que oferece atendimento semipresencial, à distância e, em seu Projeto Político Pedagógico (2017-2021), apresenta uma série de princípios que privilegiam o acesso dos estudantes a ambientes virtuais de aprendizagem: "[...] com organização de planos de estudos e tutorias para atender às necessidades individuais dos estudantes, a inserção qualificada para o mundo do trabalho e a educação permanente” (CREJA, 2017, p. 84).

O ENCCEJA é mencionado no site das secretarias dos estados do Rio Grande do Sul, Roraima, São Paulo, Paraíba, Mato Grosso do Sul, Goiás e do Distrito Federal, Brasília. Em nenhum dos sites constavam as datas $^{8}$ de aplicação da prova ou informações sobre o funcionamento do Exame. Os estados de Sergipe, Pernambuco, Pará, Mato Grosso e Bahia ainda mantêm e divulgam o serviço com o nome de "Exame Supletivo"9.

Ainda no intuito de observar outros estados que ofereçam serviços semelhantes aos NEEJAs, um levantamento foi realizado no portal do Fórum Nacional ${ }^{10}$ de EJA, também em 2017 e não foi encontrada a divulgação de iniciativas não-presenciais de Educação de Jovens e Adultos, com certificação de escolaridade.

O Fórum EJA do estado de Goiás divulgava o ENCCEJA, mas ainda o ENEM $^{11}$ como forma de certificação; o estado do Piauí menciona o CEJA, através do Fórum EJA, mas sem 
explicar o que são os CEJAs. O site do Fórum EJA do estado do Rio Grande do Sul menciona o NEEJA no seu Fórum EJA. Outro aspecto a pontuar é que, junto ao Fórum EJA do estado do Paraná, existe uma preocupação com a oferta de Educação de Jovens e Adultos na modalidade à distância. Tal preocupação é visível pela matéria divulgada no site que mostra o III Encontro de Educadores da EJA realizado em Londrina no dia 03 de março de 2017, cujo foco das discussões estava voltado para a valorização da oferta da EJA "100\% presencial $^{12 »,}$.

Catelli Jr. e Serrao (2014) ao analisar a implantação no ano de 2002 e os resultados do ENCCEJA em dez anos, considerando a referência de 2012, destacam as críticas apresentadas ao modelo de certificação nacional, que retira dos Estados a prerrogativa da certificação e acaba por fragilizar as ofertas presenciais de classes de EJA:

Entretanto, a iniciativa foi alvo de muitas críticas de pesquisadores, educadores e gestores ligados à Educação de Jovens e Adultos (EJA), uma vez que a proposta de uma política como o Encceja demonstrava reforçar um cenário em que o Estado, sobretudo a União, se retirava progressivamente da oferta direta de serviços educacionais para se transformar apenas em um regulador da sua qualidade. No caso específico da EJA, colocava-se a inadequação da criação de uma prova padronizada de abrangência nacional, desconsiderando a grande diversidade cultural existente no país e as especificidades da modalidade (CATTELI Jr.; SERRAO, 2014, p. 78).

Conforme já mencionado, a Emenda Constitucional n 59, de 11 de novembro de 2009, determinou a obrigatoriedade da escolaridade dos 4 (quatro) aos 17 (dezessete) anos, considerando essa faixa etária de atendimento, na escola básica, algo que se deu mesmo diante da determinação do artigo 38 da Lei de Diretrizes e Bases 9394/96, a seguir:

$\S 1^{\circ}$ Os exames a que se refere este artigo realizar-se-ão: I - no nível de conclusão do ensino fundamental, para os maiores de quinze anos; II - no nível de conclusão do ensino médio, para os maiores de dezoito anos. $\S 2^{\circ}$ Os conhecimentos e habilidades adquiridos pelos educandos por meios informais serão aferidos e reconhecidos mediante exames (BRASIL, 1996).

O Sistema Estadual de Educação do Rio Grande do Sul está fazendo um esforço para o cumprimento desta emenda constitucional, com a aprovação da Resolução 343/2018 pelo Conselho Estadual de Educação (CEED/RS), que em seu artigo $3^{\circ}$ estabelece:

É garantido aos estudantes de 15 (quinze) a 17 (dezessete) anos a permanência no ensino sequencial, com currículo e organização pedagógica adequados a sua faixa etária, preferencialmente no turno diurno.

$\S$ único - O estatuto da progressão parcial deverá ser previsto nos Regimentos Escolares no Ensino Fundamental - anos finais e Médio, contribuindo para a permanência e a completude do processo de aprendizagem e desenvolvimento desses estudantes na Educação Básica, desconstituindo a prática de que estudantes com 
dificuldades ou defasagem idade/etapa escolar sejam encaminhados para a EJA. A progressão parcial não se confunde com aprovação automática, constitui-se mecanismo pedagógico que permite a continuidade de estudos em disciplinas ou áreas em que o estudante não atingiu os objetivos, concomitante à aprovação para a etapa escolar seguinte (CEED/RS - resolução 343/2018).

As escolas públicas estaduais, os NEEJAs e as escolas privadas são regidas e fiscalizadas pelo CEED/RS e precisam adequar sua oferta noturna de EJA à faixa etária de 18 anos completos ou mais, tendo a preferência da frequência no período diurno os estudantes de até 17 anos.

A Resolução 343/2018 do CEED/RS favorece a aprendizagem dos adolescentes, privilegiando propostas pedagógicas específicas, como o Programa Trajetórias Criativas ${ }^{13}$, no esforço da permanência do jovem até os 17 anos na escola regular durante o período diurno.

Abordaremos a seguir aspectos relacionados aos NEEJAs, que compõem o sistema estadual de educação do estado do Rio Grande do Sul como modalidade não-presencial de EJA, sendo o único representante público e gratuito neste segmento. Sua origem está relacionada aos antigos supletivos, constando como instituições oficiais na oferta de certificação de conclusão do Ensino Fundamental e do Ensino Médio, através da aprovação dos estudantes em provas fracionadas por área do conhecimento, a exemplo do ENEM: Ciências da Natureza, Ciências Humanas, Matemática e Linguagens; ou por componente curricular organizado em 14 disciplinas no Ensino Médio e 8 disciplinas no Ensino Fundamental, sendo que cada núcleo tem autonomia na organização das provas e ficando a certificação a cargo da Secretaria Estadual de Educação (SEDUC/RS). Diante dessa organização, os NEEJAs aplicam as provas e remetem os resultados para a SEDUC/RS expedir os certificados de Ensino Fundamental ou de Ensino Médio para os estudantes.

A rede dos NEEJA do Rio Grande do Sul é composta por 28 Núcleos, presentes em 23 cidades das diversas regiões do estado, cuja extensão territorial é de 281.748 km², com 497 municípios, conforme o mapa abaixo: 
Figura 1 - Mapa da Localização dos NEEJAs no Rio Grande do Sul

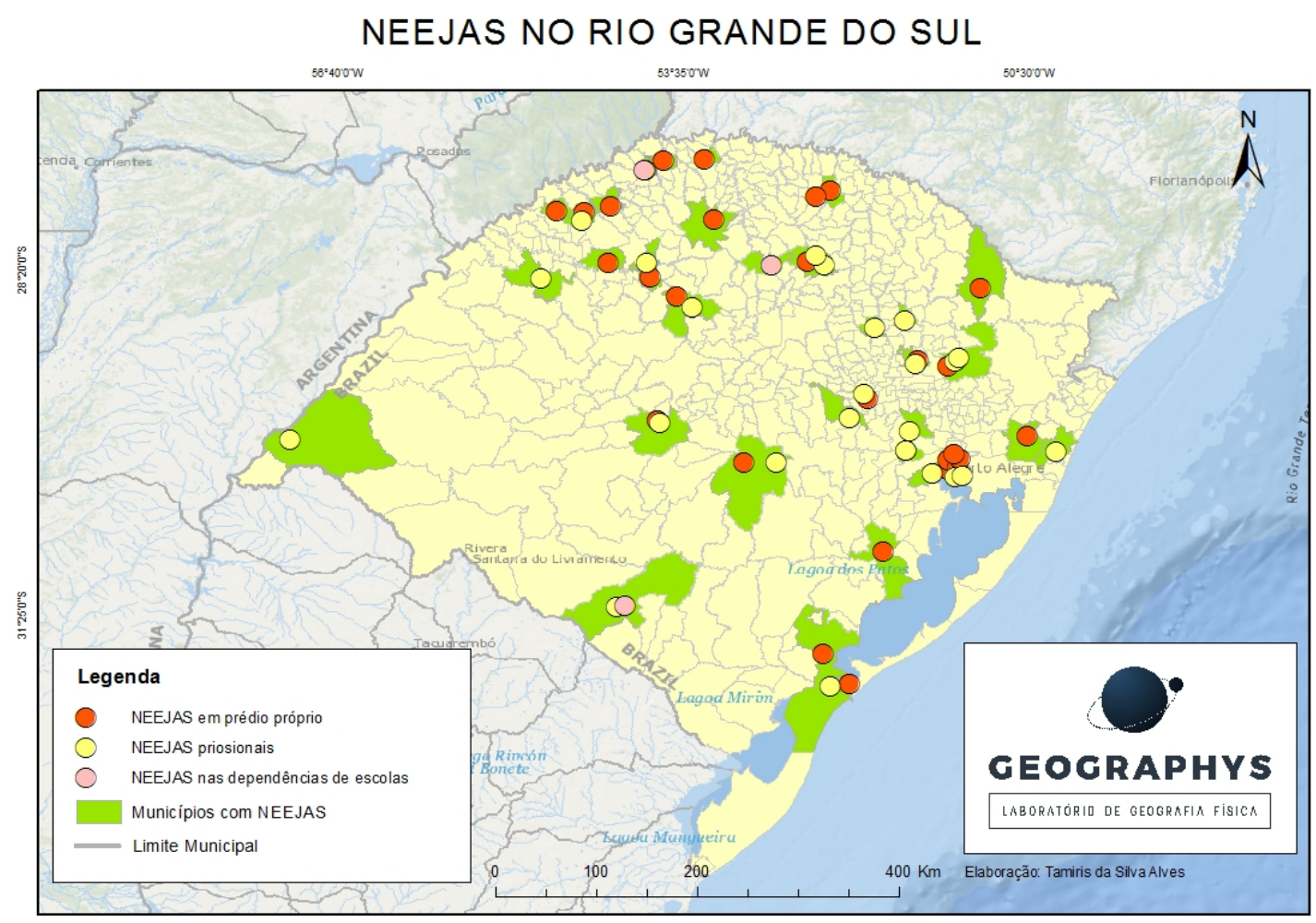

Fonte: Elaboração de Tamiris da Silva Alves.

Dos 28 Núcleos, cinco estão localizados na capital Porto Alegre e foram envolvidos na pesquisa de abordagem qualitativa, com registros em diários de campo de caráter etnográfico, no período de agosto 2016 até dezembro de 2017, a saber: NEEJA Darcy Vargas, NEEJA Paulo Freire, NEEJA Darcy Ribeiro, NEEJA Cardeal Alfredo Vicente Scherer e NEEJA Menino Deus.

Conforme o mapa, estão ainda vinculados à Secretaria de Segurança Pública do estado 14 Núcleos Prisionais não envolvidos na pesquisa, destinados a estudantes com cerceamento de liberdade. As três recorrências indicadas pela cor rosa correspondem aos NEEJAs que não possuem prédio próprio e por isso funcionam em escolas regulares estaduais e estão localizados no interior do estado.

A escolha dos cinco núcleos presentes na capital do Estado para a pesquisa qualitativa ocorreu pela representatividade da capital, seja pela demanda de jovens e adultos sem Educação Básica completa, seja pela facilidade de acesso aos estudantes, pois dois dos núcleos estão localizados no centro da cidade: NEEJAs Darcy Vargas e NEEJA Cardeal Alfredo Vicente Scherer; outros situam-se em áreas residenciais de classe média onde estão localizados postos de trabalho vinculados ao setor de serviços (vigilância, limpeza) e 
comércio, como o NEEJA Paulo Freire (localizado no bairro Auxiliadora) e o NEEJA Menino Deus que leva inclusive o nome do bairro. Os estudantes trabalham nestes bairros e neles permanecem após seu turno de trabalho para completar a Educação Básica. Há, ainda, o NEEJA Darcy Ribeiro, que completou a abrangência da pesquisa vinculada ao entendimento da experiência dos NEEJAs da capital. Todos os cinco NEEJAs de Porto Alegre funcionam em prédios próprios, não dividem espaço físico em prédios de escolas públicas regulares, como ocorre em algumas situações no interior do estado, conforme registro do mapa.

No primeiro contato com os Núcleos, através da equipe de coordenação pedagógica e diretoria, foram utilizadas entrevistas semiestruturadas sobre os aspectos gerais do funcionamento dos núcleos, direcionando-se também para o entendimento das metodologias e concepções de aprendizagem existentes, bem como da relação dos núcleos com o mundo do trabalho.

A percepção das entrevistas como "situações de interação humana” (SZYMANSKY, 2011) entre pessoas com expectativas e emoções em relação a elas e nas quais o entrevistador-pesquisador, em sua interação com o entrevistado busca seguir uma estrutura de perguntas que pode ser flexível conforme os rumos da conversa, deve também pressupor que "não há roteiro fechado", sinalizando que "os objetivos da entrevista devem ser claros".

O roteiro da entrevista tinha como pontos principais: (1) o número de alunos matriculados e o número de alunos formados; (2) o número e o tipo de vínculo dos professores; e (3) as estratégias pedagógicas e as práticas dos NEEJA.

As entrevistas semiestruturadas ocorreram nos dois primeiros encontros junto a cada Núcleo. No primeiro encontro, somente com a equipe gestora e no segundo, com os professores que se dispuseram a colaborar com a pesquisa. Os temas da entrevista semiestruturada foram: (1) a carreira docente, em especial no NEEJA; e (2) as práticas educativas do professor no estabelecimento de ensino. Nesse trabalho de pesquisa nos NEEJAs, houve em cada um o envolvimento, respectivamente, das professoras das seguintes áreas: Física, Literatura, a classe de Alfabetização dos jovens senegaleses, Espanhol e, da professora envolvida com os estudantes surdos.

Em todos os cinco NEEJAs da capital, poucos professores eram contratados, sendo o quadro composto em sua maioria por professores concursados do Estado.

O terceiro encontro voltou-se para a observação de um turno de apoio e de provas realizadas no local, sendo registradas aulas para grupos maiores e os "tira dúvidas", para grupos menores, bem como atendimento individual de estudantes em horários determinados pelos professores e divulgados no mural do NEEJA.

$\mathrm{Na}$ quarta visita, de modo informal, foram entregues pelos pesquisadores materiais formativos voltados para a educação de jovens e adultos junto aos cinco NEEJAs.

Visitas e observações adicionais foram realizadas para casos específicos, como o da turma de alfabetização presente em um dos NEEJAs com jovens de origem senegalesa. Todas as observações e informações obtidas foram registradas em diários de campo.

A análise dos dados da pesquisa ocorreu conforme a base interpretativa da análise de conteúdo (BARDIN, 2011) constituída pelos seguintes temas balizadores: (a) os sujeitos 
participantes da pesquisa, especialmente as equipes gestoras e professores dos NEEJAs que, a despeito da existência do Regimento Padrão de Funcionamento ${ }^{14}$, possuem modos próprios de operar as rotinas das provas certificadoras e encontros de "tira dúvidas"; (b) a relação entre os pesquisadores (professora responsável e bolsistas de iniciação científica) se realizou de forma dialógica, sendo que em um dos NEEJAs foi proposta da equipe da pesquisa uma reunião de formação considerando a possibilidade de novas estratégias pedagógicas, iniciativa que não foi possível ser continuada; (c) as entrevistas ocorreram por adesão de integrantes das equipes pedagógicas e de professores de cada um dos cinco NEEJAs; e (d) o modelo de aferição por provas para certificação de nível de escolaridade, que revela-se insuficiente para o reconhecimento de saberes do trabalho e da experiência do trabalhador.

Em um NEEJA, foi possível o envolvimento da pesquisa em uma reunião com o conjunto de professores que atuavam tanto nas provas e encontros "tira dúvidas" do Ensino Fundamental, quanto nas provas e encontros "tira dúvidas" do Ensino Médio. A reunião, de caráter formador e proposta pela equipe diretiva, buscou a reflexão sobre as possibilidades de ampliação dos materiais pedagógicos e a elaboração de um aplicativo para o celular pelo qual se pudesse disponibilizar materiais para os estudantes, considerando a experiência de um blog desenvolvido pelo professor de Artes Visuais e pela professora de Ciências Biológicas. Esse modelo de reunião não teve continuidade, pois não foi possível conciliar novas agendas junto à coordenação pedagógica.

As provas fracionadas, por sua vez, consistem em avaliações para cada disciplina ou por área do conhecimento em cada nível de Ensino - Fundamental e Médio - e estruturam dificuldades no processo de avaliação, pois determinam o aprendizado através de questões cujas respostas são restritamente avaliadas em corretas ou incorretas. Esse modelo avaliativo não está de acordo ao modo proposto e idealizado pelo Regimento Escolar Padrão dos NEEJAs do Rio Grande do Sul, que indica avaliações em conformidade a todos os aspectos e componentes, considerando especialmente a diferença considerável existente entre as matrículas e os estudantes efetivamente certificados.

O conteúdo das provas fracionadas é principalmente apresentado nas apostilas elaboradas pelos professores do núcleo, material preparatório para a aprovação. A orientação é que o estudante estude em casa, fora do ambiente do NEEJA.

Esse material didático é específico de cada NEEJA e não possibilita que o estudante realize provas em outro estabelecimento. Além disso, foi possível observar erros conceituais existentes, sobretudo no material do ensino de Física para o Ensino Médio em um dos NEEJAs, bem como o valor abusivo cobrado em relação ao orçamento dos jovens e adultos trabalhadores que buscam a realização das provas: em torno de R \$ 100,00 para a impressão das apostilas de todas as disciplinas do Ensino Fundamental ou do Ensino Médio, de acordo com o levantamento de dados da pesquisa, no segundo semestre de 2016.

Em um dos núcleos, foi ponderado em uma das entrevistas acerca do valor que deveria ser desembolsado pelo estudante para a realização das fotocópias das apostilas, sendo argumentado o seguinte por uma pessoa da gestão do NEEJA: "alguma contrapartida o estudante deve dar”. Entende-se como complicada tal contrapartida, até porque a leitura das apostilas não revela bom desempenho nas provas fracionadas; a equipe diretiva desse mesmo 
NEEJA afirma que existem instituições privadas no centro de Porto Alegre que cobram mensalidade e preparam para as provas que ocorrem no NEEJA. Logo, há uma procura de aprovação nas provas de uma instituição pública, sendo esse estudante preparado em aulas de uma instituição privada, comprovando a possível deficiência dos atendimentos individuais e/ou em grupo desse núcleo específico.

Também foi possível constatar a pouca utilização de ambientes digitais para o ensino nos NEEJA de Porto Alegre. Em especial, plataformas virtuais com conteúdo estão totalmente ausentes, e muitos dos núcleos pesquisados não possuem qualquer tipo de endereço eletrônico (site). Não há uma plataforma governamental online para acesso ao conteúdo ou mesmo um trabalho para sua unificação virtual. Devido à precariedade das condições do espaço físico, o acesso à internet nos locais é dificultado.

Os cinco núcleos de Porto Alegre contam com salas e equipamentos para laboratórios de informática, mas sem técnicos-administrativos destinados ao ambiente e sem manutenção das máquinas. O Parecer 765/2015 que regulamenta os NEEJAs, em seu item 9.2, apresenta o Laboratório de Informática como um dos Serviços de Apoio Pedagógico:

O Laboratório de Informática é o espaço no qual a tecnologia é utilizada pelo professor e pelo aluno, inserido nas atividades pedagógicas. Tem por objetivo que o aluno aprenda, utilizando as tecnologias como ferramentas que o apoiem no processo de reflexão e de construção da aprendizagem, nas áreas do conhecimento e dos componentes curriculares (CEED-RS, 2015b, p. 11).

Também não há uma plataforma digital institucional capaz de disponibilizar os conteúdos selecionados pelo professor e de servir como aporte para a comunicação entre professor e estudante para além dos momentos presenciais de apoio, a fim de potencializar tais encontros. Cabe mencionar que a biblioteca estava aberta durante as visitas junto aos cinco núcleos, com horários alternativos para uso dos professores e estudantes.

O celular, hoje de fácil acesso também ao público da EJA, não é utilizado como um possível recurso didático por meio do trabalho com mensagens, sites ou aplicativos educativos. Há um potencial nesses dispositivos móveis e aplicativos que podem ser explorados de maneira criativa como recurso didático pelo NEEJA.

Assim como a maioria dos estudantes da EJA, a grande maioria dos estudantes dos NEEJAs são trabalhadores que se tornam estudantes para melhorar sua posição no mercado de trabalho, acessar curso técnico ou entrar na universidade. Uma das equipes gestoras relatou casos de estudantes que procuram o Núcleo para certificar o Ensino Médio após terem sido aprovados em concurso público.

No entanto, a conexão entre os saberes do trabalho e os conteúdos escolares é inexistente nas provas e nas apostilas dos NEEJAs de Porto Alegre e, sem a ligação direta e intencional do trabalho com a aprendizagem, ele se torna apenas uma possível consequência da certificação.

Realizamos também um levantamento nas redes sociais para verificar a presença dos NEEJAs. Três núcleos de Porto Alegre possuem páginas no Facebook. Aquele com maior 
repercussão nessa rede social durante o período da pesquisa correspondeu ao NEEJA Cardeal Alfredo Vicente Scherer, embora o administrador da página não seja ligado ao Núcleo, conforme informou a equipe diretiva.

Quanto à Educação Profissional, os NEEJAs não consideram de maneira direta as experiências profissionais e vivências de seus estudantes, não sendo tema presente nas provas fracionadas. De modo indireto, entretanto, há abordagens sobre temas da vida profissional, em especial no contato com o professor ou com a professora nos encontros "tira dúvidas", de apoios e na classe de alfabetização.

Diante desse contexto, é emergente refletir sobre experiências de certificação de aprendizagem de jovens e adultos trabalhadores no contexto da escolaridade proporcionada pelos NEEJAs, em que o professor ou a professora elabora e aplica a prova da sua disciplina ou da área do conhecimento, considerando os conteúdos necessários para a sua certificação. Entretanto, essa prova não reconhece necessariamente os saberes do trabalho, os saberes da experiência desse estudante, que pode ser uma dona de casa, um motorista de ônibus, um pedreiro ou um estudante da escola básica com histórico de reprovações.

A certificação profissional dos saberes do trabalho, instituída pelo Programa CERTIFIC em integração com o atualmente extinto Ministério do Trabalho e Emprego e do Ministério da Educação através da Portaria Interministerial No 1.082 de 20/11/2009 ${ }^{15}$, pressupõe como requisito mínimo o Ensino Fundamental completo para qualquer certificação profissional, sendo a rede federal de Educação Profissional Científica e Tecnológica a responsável pela organização desta política pública. São cinco as áreas profissionais que atualmente o CERTIFIC abrange: Pesca, Música, Turismo e Hospitalidade, Construção Civil e Eletroeletrônica, com 39 perfis profissionais aprovados em consonância com a concepção de competências.

Conforme dados extraídos de documentos do Ministério da Educação, junto à Diretoria de Políticas da Educação Profissional e Tecnológica no período de 2010 a 2012 foram inscritos 3.243 trabalhadores para reconhecimento de saberes profissionais. Efetivamente, foram certificados com conclusão do Ensino Fundamental, equivalente a 9 anos de estudo, compreendendo 117 trabalhadores nos perfis profissionais: preparação de pescado higienização; eletricista; eventos de hotelaria; pedreiro e pescador artesanal de água doce. Estavam em processo de reconhecimento de saberes, em agosto de 2012, 1.048 trabalhadores. A evasão de 2.078 trabalhadores durante o processo teve como fator principal a não frequência às classes de Educação de Jovens e Adultos do Ensino Fundamental nas redes municipais de Ensino. Coloca-se, dessa forma, o desafio para a certificação profissional também validar conhecimentos escolares, a exemplo da experiência de Portugal, que possui um sistema nacional de reconhecimento, validação e certificação de competências profissionais tanto no nível básico (nossa Educação Fundamental) quanto no secundário (nosso Ensino Médio).

A experiência do CERTIFIC do Brasil possui intercâmbio com a Validação de Experiências Adquiridas (VAE) da França, como parte de um acordo de cooperação entre os Ministérios da Educação da França e do Brasil, segundo consta na página eletrônica do Instituto Federal de Santa Catarina (IFSC - Florianópolis, 2011): 
Os resultados obtidos com o Programa de Certificação Profissional e Formação Inicial e Continuada (CERTIFIC) no Campus Florianópolis-Continente foram compartilhados nesta semana num encontro, em Brasília, que reuniu profissionais de instituições de ensino superior do Brasil e da França para tratar sobre a certificação profissional no Brasil e a Validação de Experiências Adquiridas (VAE). Durante o evento, a coordenadora da comissão do CERTIFIC do campus, Emanoelle Fogaça Marcos, apresentou o trabalho desenvolvido no ano passado com cerca de 100 profissionais. O IFSC é, até o momento, a única instituição que conseguiu chegar à última etapa do programa de certificação promovido pelo Ministério da Educação, através da Secretaria de Educação Profissional e Tecnológica.

Experiência do CERTIFIC do Campus Florianópolis Continente é destaque internacional (IFSC, 2011, online).

Aos currículos do CERTIFIC, coloca-se o desafio de reconhecer as aprendizagens dos trabalhadores como componentes curriculares, sem partir do conhecimento dos alunos para nunca mais voltar, mas sim de fato voltar, ou seja, proporcionar uma escuta sensível aos saberes dos alunos para articulá-los aos conteúdos escolares, sendo estes desenvolvidos através de projetos interdisciplinares de pesquisa, com envolvimento de grupos de professores e alunos, estabelecendo a integração do então denominado saber científico, constituinte histórico dos currículos escolares, ao saber popular.

No CERTIFIC é possível vislumbramos o currículo, e aí o processo de ensinoaprendizagem como uma fagocitose da Educação Profissional com a Educação Geral. Para o filósofo argentino Rodolfo Kusch (1986), o mestiço é resultado do encontro entre o europeu colonizador e o indígena que estava na América, constituindo-se como uma fagocitose desse encontro. As novas estruturas culturais que se desenvolvem a partir da presença europeia na América são colaboradoras de um processo de fagocitose, com o novo que se apresenta, nem europeu, nem indígena, mas consequência do ser europeu (da mudança, da racionalidade) e do estar indígena (da tradição, da contemplação).

Considerando a obra de Rodolfo Kusch, o currículo da Educação Profissional fagocita o da Educação geral, tornando necessário um repertório da formação geral vinculado à escrita, ao raciocínio matemático, à fruição à língua estrangeira, aos saberes científicos e das artes, aos saberes da história da humanidade, ao entendimento do espaço em se encontra o estudante para a formulação das bases curriculares do posto de trabalho a qual o curso está vinculado.

Isto quer dizer que, para cursos técnicos como Agropecuária, Edificações, Informática e Enfermagem, há um conjunto de saberes gerais que potencializam os saberes específicos construídos historicamente para dar conta do ofício, da atuação profissional dentro da sociedade.

O entendimento de um currículo integrado ${ }^{16}$ baseado na obra de Kusch possibilita a formação do trabalhador valorizando suas experiências na proposição de reconhecimento e certificação de saberes, a exemplo das experiências relatadas em Portugal e na França.

A elevação de escolaridade promovida pelos NEEJAs não compõe reconhecimento de saberes e competências, a exemplo das políticas de Validação de Saberes e Competências 
(VAE) da França ${ }^{17}$ e do sistema português, vinculado aos Centros Novas Oportunidades, analisados por Cavaco em sua pesquisa, porque "O referencial de competências revelou-se um importante instrumento de trabalho das equipas, mas que, na opinião de vários interlocutores, deve ser alvo de aperfeiçoamento e adequação" (2008, p. 213).

A título de ilustração comparativa, os cursos de Educação/Formação de Adultos em Portugal são inovadores por seus formatos curriculares, os quais:

i) contemplam uma articulação entre formação de base e a formação profissionalizante; ii) o percurso formativo é baseado num referencial de competências-chave; iii) o processo de reconhecimento e validação de competências deve permitir a identificação dos adquiridos experienciais dos formandos e a definição de percursos individualizados de formação; iv) a figura do mediador que visa assegurar o acompanhamento dos formandos e equipas pedagógicas ao longo da formação; v) o módulo Aprender com Autonomia que se destina a identificar e promover estratégias de autoformação; vi) o Tema para a Vida que se inspira numa estratégia de transversalidade dos saberes e exige uma articulação entre os vários formandos (CAVACO, 2008, p. 208-209).

Nas últimas duas décadas, a experiência portuguesa em Educação de Adultos apresenta propostas inovadoras ao então Ensino Recorrente, denominado no Brasil como Ensino Regular. Os cursos de Educação / Formação de Adultos (EFAS) apresentam elevada adesão e motivação dos adultos, bem como a aprovação nos Centros de Reconhecimento, Validação e Certificação de Competências (CRVCC).

O reconhecimento desses currículos da experiência portuguesa apresenta outras possibilidades de reflexão para a experiência brasileira:

Em Portugal, com o objetivo de relançar uma política de Educação de Adultos de vanguarda que chegasse a uma grande parte da população com baixa escolaridade, foram criados os Centros de Reconhecimento, Validação e Certificação de Competências (CRVCC, pela anterior Agência, ANEFA, através da portaria 1082A/2001 de 5 de setembro), aos quais se sucederam os Centros Novas Oportunidades (CNOs), através da portaria 370/2008 de 21 de maio, com o objetivo de elevar a escolaridade e a qualificação profissional dos adultos através do reconhecimento, validação e certificação de competências escolares e profissionais, adquiridas através da experiência de vida, particularmente em contextos informais e não formais. Os destinatários eram os adultos que tinham mais de 18 anos e que já possuíam competências e saberes, fruto das suas experiências de vida e de trabalho e que pretendiam vê-las reconhecidas formalmente (MORAIS; OLIVEIRA, 2018, p. 325).

O texto das professoras Morais e Oliveira atualiza a pesquisa de Cavaco, registrando que atualmente há a necessidade de frequência dos jovens e adultos em cursos de 50 horas, os quais realizam provas de aferição de competências e saberes com os estudantes que se candidatam a determinadas possibilidades de reconhecimento. Na experiência anterior dos 
Centros Novas Oportunidades, estes desenvolviam a escrita da trajetória de vida com os estudantes e, a partir delas, eram extraídas e certificadas as experiências de trabalho e escolarização dos estudantes maiores de 18 anos. Sendo possível, após tais certificações, baseadas na análise das histórias de vida, ocorria o encaminhamento para cursos de formação profissional e/ou módulos de elevação de escolaridade. E no mesmo Centro ${ }^{18}$, muitas vezes em uma escola pública de Educação Básica, podia ser realizada tanto a certificação dos saberes profissionais quanto dos saberes do nível de escolaridade.

\section{Certificação da Aprendizagem e Certificação da Escolarização}

A distinção realizada entre aprendizagem e escolarização ocorre porque no Brasil a obrigação em relação ao trabalho é vinculada à escravidão até 1888, sendo a obrigatoriedade e a gratuidade da escolarização só efetivamente garantida pela Constituição Cidadã de 1988.

Nesse sentido, os saberes valorizados pela escola, incluídos em seu currículo, em seu fazer pedagógico, tem dialogado muito pouco com os saberes valorizados pelo público da EJA, configurando-os como figuras de desordem e isso quando conseguem ser estudantes, quando conseguem acessar a escolarização:

A desordem e o caos não estão somente situados, estão exemplificados: à topologia imaginária, simbólica, associa-se um conjunto de figuras que manifestam sua ação dentro do próprio espaço policiado. Figuras ordinárias, no sentido de que se encontram banalmente presentes dentro da sociedade, mas em situação de ambivalência por aquilo que é dito delas e aquilo que elas designam. Complementar e subordinadamente, elas são o outro objeto de desconfiança e de medo em razão de sua diferença e de seu status inferior, causa de suspeita e geralmente vítima de acusação (BALANDIER, 1997, p. 103).

Esse jovem, adulto ou idoso, que não completou a Educação Básica, compõe figura de desordem em uma sociedade antes industrial e hoje uma sociedade da informação, da comunicação, pelas novas mídias digitais e pelo advento da informática.

A certificação dos saberes é, como vimos, preterida em relação à certificação da escolarização e às experiências de validação de saberes e experiências dos jovens e adultos que não completaram com regularidade seus estudos, mesmo diante da nova regulamentação da LDB, modificada pela lei 13692/2018.

Constante na redação dessa mesma lei, a perspectiva da aprendizagem ao longo da vida, se por um lado amplia as possibilidades de formação das pessoas, também destaca os processos de aprendizagem dentro e fora do sistema escolar.

O reconhecimento da herança histórica vinculada à abolição do trabalho escravo que só ocorreu em 1888 permite compreender dificuldades atuais ainda não superadas como a negação do saber dos estudantes jovens, adultos e idosos em provas fracionadas, com conteúdo pouco ou nada relacionado ao seu cotidiano, aos seus interesses. Mas, por outro 
lado, alternativas estas necessárias para esse público em despejo, como nomeia Carolina Maria de Jesus (2014), excluído, outsider, como descreve Norbert Elias (2000), como vidas desperdiçadas, conforme Bauman (2005) e figuras de desordem, para Balandier (1997), ou seja, os estudantes da EJA.

Julgar que o pobre é pobre porque não quer aprender e lhe "concedendo" aprendizagem - "qualquer coisa serve", "qualquer um pode ensinar esse matuto" - são preconceitos a serem enfrentados pelas políticas públicas da Educação de Jovens e Adultos.

Peter Jarvis, falecido em novembro de 2018, professor de Educação Permanente na Universidade de Surrey do Reino Unido, vinculou sua produção à Educação de Adultos e à Educação ao longo da vida. No Brasil, estão publicados um capítulo de sua autoria no livro Teoria Contemporâneas de Aprendizagem, organizado por Illeris (2013) intitulado Aprendendo a ser uma pessoa na sociedade: aprendendo a ser eu, e um artigo na Revista Educação \& Realidade, sob o título Aprendizagem implícita e explícita. A maioria das suas publicações encontram-se na sua língua materna: o inglês.

A obra de Jarvis, dentre outros autores que produzem sobre uma Pedagogia para Adultos ${ }^{19}$, destaca a mudança no jovem, no adulto e no idoso que aprende. $\mathrm{O}$ autor escreve sobre um processo de disjunção na medida em que há uma procura, uma busca desses trabalhadores por formação, caracterizado pelo autor como motivação, um processo de mudança, de desacomodação diante de determinado repertório de aprendizagem, que pode estar vinculado à escolarização ou não, na perspectiva da aprendizagem ao longo da vida. Jarvis considera haver aprendizagem, portanto, na Educação de Adultos, quando ocorre uma mudança no sujeito, a disjunção, também traduzida do inglês por disjuntura:

A aprendizagem humana é a combinação de processos ao longo da vida, pelos quais a pessoa inteira - corpo (genético, físico e biológico) e mente (conhecimento, habilidade, atitudes, valores, emoções, crenças e sentidos) - experiencia as situações sociais, cujo conteúdo percebido é transformado no sentido cognitivo, emotivo ou prático (ou por qualquer combinação) e integrado à biografia individual da pessoa, resultando em uma pessoa continuamente em mudança (ou mais experienciada) (JARVIS, 2013, p. 35-36).

Considerando os processos de aprendizagem diante de uma mudança, uma disjunção, uma modificação de comportamento, renovação ou constituição de conteúdo, as quais repercutem na ocupação profissional, como argumenta Jarvis (2013), a aprendizagem é existencial e experiencial. Novamente, cabe refletir sobre os processos de certificação de escolarização, os quais vão ao encontro do que o autor argumenta como teorias de aprendizagem incompletas, as que não consideram as aprendizagens implícitas:

[...] a aprendizagem explícita e implícita constitui, provavelmente, duas formas diferentes de aprendizagem e que ambas se reportam ao que internalizamos como resultado de nossas experiências - a explícita é consciente, mas a implícita se relaciona com aspectos não conscientes ou não voluntários da experiência. Mas essa última experiência parece não envolver a mente da mesma forma como o faz a 
anterior. No entanto, todas as nossas sensações são inicialmente sensações corporais e assumimos que essas sensações são transmitidas para o cérebro através do sistema nervoso e outros sistemas corporais: muitos dos quais formam a consciência e constituem a mente - porém nem todas essas experiências estão registradas na mente. Poderíamos dizer que um pouco da aprendizagem é corporal ou cerebral, em oposição à aprendizagem mental - e eu não as considero como experiências reprimidas (JARVIS, 2015, p. 823).

Evidentemente, as provas que conferem a aprovação de um estudante, em uma disciplina específica, compõem aferição de aprendizagem explícita, resultado muitas vezes de um treino para responder às questões, uma esperteza desenvolvida pela prática na participação em processos seletivos. Através delas, não é, entretanto, possível reconhecer os saberes implícitos, tampouco os saberes da experiência, que constituem o ser como pessoa, como self, conforme Peter Jarvis.

A certificação da escolarização para jovens, adultos e idosos subtraídos do direito à educação, compõe incompletude, ou seja, não valoriza as aprendizagens adquiridas em suas trajetórias de vida, mas reflete e visa somente a necessidade diante da demanda por escolarização básica para as pessoas maiores de 18 anos.

No Brasil, há demanda significativa para Educação de Adultos, pois a metade da população (50,2\%) com idade acima de 10 anos, ou seja, 81,3 milhões de pessoas, não conseguiu completar o Ensino Fundamental, conforme dados do censo demográfico realizado pelo Instituto Brasileiro de Geografia e Estatística (IBGE) em 2010. Já com Ensino Médio incompleto, de 3 a 4 anos de estudo, dos 15 aos 18 anos de idade, correspondendo à etapa complementar à denominada Educação Básica, são mais 28,7 milhões. Há, ao todo, portanto, 110 milhões de brasileiros sem ter completado a primeira e a segunda fase da Educação Básica.

Conforme dados da mesma pesquisa do IBGE, especificamente no estado do Rio Grande do Sul, 43,70\% da população com mais de 18 anos não possui o Ensino Médio concluído. Em relação ao Ensino Fundamental, 18,26\% da população não concluiu essa etapa.

Por outro lado, uma pesquisa da Fundação Getúlio Vargas baseada em dados da Pesquisa Mensal de Emprego, também formulada pelo IBGE, no acumulado dos anos 2002 a 2010 afirma que cursos profissionalizantes de Formação Inicial e Continuada não atingem empregabilidade, tampouco níveis salariais melhores para os trabalhadores. Já a elevação de escolaridade, sobretudo de nível médio, corrobora para o aumento salarial em até 50\%, tratando-se de vagas de emprego no serviço público.

O perfil dos estudantes da Educação de Jovens e Adultos, segundo Jane Paiva (2017), vem se alterando há algum tempo, principalmente no que diz respeito aos motivos que levam esses jovens e adultos a procurarem a EJA. Se antes o público era formado por adultos que não frequentaram a escola ou dela saíram muito cedo, hoje é formado por jovens e adultos que frequentaram a escola, porém fracassaram ou foram fracassados por ela. Nesse sentido, a Resolução 343/2018 do Conselho Estadual de Educação do Rio Grande do Sul (CEED/RS) compõe peça legislativa fundamental para garantir a frequência dos jovens até os 17 anos na 
escola regular, no período diurno sendo que a experiência dos NEEJAs de Porto Alegre com a certificação do Ensino Fundamental e do Ensino Médio para os maiores de 18 anos, precisa ser valorizada.

\section{Conclusão}

[...] eu estou contente com os meus filhos alfabetizados. Compreendem tudo. O José Carlos disse-me que vai ser um homem distinto e que eu vou tratá-lo de seu José. Já tem pretensões: quer residir em alvenaria (JESUS, 2014, p. 140).

A relevância dada por Carolina Maria de Jesus à alfabetização de seus filhos se justifica por sua compreensão diante de seu cotidiano na cidade de São Paulo na década de 1950 e sobre a utilidade da leitura, bem como sua relação com a escrita para a resiliência em relação à fome e às péssimas condições de moradia. Ainda segundo as palavras da autora, “[...] os políticos sabem que eu sou poetisa. E que o poeta enfrenta a morte quando vê o seu povo oprimido” (JESUS, 2014, p. 39).

O ver-se como poeta e o sentido da poesia para denunciar, para contar o abuso, os maustratos de crianças e mulheres na favela é caracterizado pela autora como quarto de despejo do palácio, que é a cidade de São Paulo. Casos por ela relatados como a cobrança arbitrária da luz por um morador individual; a busca de água em uma torneira coletiva; a falta de dinheiro para comprar sabão para lavar a roupa; fizeram Carolina Maria de Jesus, com apenas dois anos de escolaridade básica, uma mulher-escritora-negra-mãe cuja obra justifica a relevância das políticas sociais atuais, como o Bolsa Família, a distribuição nacional de merenda escolar, que se pretendem como meios para coibir a fome, descrita por ela como amarela: “[...] resolvi tomar uma média e comprar um pão. Que efeito surpreendente faz a comida no nosso organismo! Eu que antes de comer via o céu, as árvores, as aves tudo amarelo, depois que comi, tudo normalizou-se aos meus olhos” (JESUS, 2014, p. 44).

A importância da escolarização destacada por Carolina Maria de Jesus é base para a atual reflexão que analisa os resultados da citada pesquisa desenvolvida junto aos Núcleos de Educação de Jovens e Adultos localizados na cidade de Porto Alegre, pela certificação de Ensino Fundamental e Médio para pessoas de 18 anos e mais, embasados pelo parecer 765/2015 e resolução 343/2018 do Conselho Estadual de Educação (CEED/RS).

Os NEEJAs prisionais, não incluídos na pesquisa empírica, nos parecem um modelo adequado de oferta de elevação de escolaridade, certificação de aprendizagem de pessoas privadas de liberdade, por seu caráter de atendimento individualizado, "provas e testes livres”, ou seja, a qualquer tempo, constituem-se em experiências possíveis para estudantes de diferentes tempos de permanência no estabelecimento penal, atrelados ao cumprimento de sua pena.

Entre o que se observou nos NEEJAs de Porto Alegre, como resultados da pesquisa, é possível destacar: a flexibilidade do ensino, em especial os horários flexíveis para o educando e educador, possibilitando o atendimento aos alunos trabalhadores em seus horários 
disponíveis; um grande potencial para a vinculação com a Educação Profissional, que pode ainda ser explorado para melhorar a qualificação dos jovens e adultos concluintes dos NEEJAs; as peculiaridades no trabalho docente, no qual se destaca o ensino da Língua Portuguesa para estrangeiros, especialmente senegaleses; a conformação de uma classe de pessoas surdas em um dos NEEJA, composto por uma sala de recursos equipada, centralizando o atendimento das pessoas com necessidades educativas especiais; e a experiência de um dos NEEJA na aplicação de provas nos finais de semana para estudantes do interior do estado.

As provas fracionadas, conforme aqui questionadas, compõem dificuldades da estrutura de avaliação, visto que ainda reportam aos antigos Exames Supletivos, com materiais didáticos de apoio desatualizados e pouco atraentes para estudo individual. Nessa estrutura são ofertadas três opções de exames: por componente curricular (o candidato faz um exame para cada disciplina), por área de conhecimento (o candidato faz um exame para cada área de conhecimento) e prova única (o candidato faz um exame para concluir o Ensino Fundamental ou Médio). Até o ano de 2017 ainda era possível o aproveitamento do ENEM para certificação, modificada pelo governo de Michel Temer através do Decreto 9.432/2018. Com a mudança, embora continue uma importante porta de acesso para o Ensino Superior, o ENEM apenas afere o domínio de competências e habilidades do Ensino Médio, mas não mais certifica o Ensino Médio.

A certificação dos níveis de ensino cabe então ao ENCCEJA, sem oportunizar o acesso ao Ensino Superior, perpetuando o local de exclusão das classes populares para as quais as oportunidades são escassas e desiguais.

A experiência do CERTIFIC, assim como as experiências dos NEEJAs, indica a necessidade da constituição de um currículo voltado para jovens e adultos que trabalham, ou que querem trabalhar e não dispõem de acesso ou condições de permanência na escola regular.

Neste currículo integrado, o ensinar e o aprender compõem um ser ensinado ancorado no modelo moderno de escola, como Kusch (1986) elabora o ser europeu, para um aprender vinculado ao inusitado, no reconhecimento de que a aprendizagem ocorre nas e pelas oficinas culturais; nas e pelas saídas de campo; pela promoção de acordo com as etapas de aprendizagem, rompendo com a constituição das séries anuais com a promoção do aluno atrelada às horas, aos dias frequentados; e inaugurando a promoção do aluno a qualquer tempo pela sua compreensão e apropriação da aprendizagem, pelas suas experiências profissionais, pela constituição e valorização de sua história de vida. O jovem, o adulto trabalhador de classe popular tem pressa, porque por suas trajetórias há expectativas emergenciais à elevação de escolaridade, à certificação profissional, que, de modo geral, compreendem melhorar sua condição de trabalho, comunicar-se melhor com as pessoas, ter assunto, colaborar com as lições dos filhos na escola, fazer a carteira de motorista, entre tantas outras demandas.

As experiências de certificação de saberes do trabalho e do currículo da Educação Básica de Portugal e da França são inspiradoras para a expansão do CERTIFIC e a formulação de um currículo na EJA valorizador das experiências dos trabalhadores, um currículo resultado 
da fagocitação da formação geral pela formação do trabalho, em um encontro entre movimento e repertório geral. Desse encontro resultaria o currículo integrado da formação do trabalhador, do reconhecimento de seus saberes e experiências.

Diante da demanda por Educação de Jovens e Adultos no Rio Grande do Sul e conforme os dados estatísticos e empíricos apresentados, os NEEJAs podem ser interpretados como inéditos viáveis, conforme a perspectiva de Paulo Freire (2011), assim como o CERTIFIC, o CREJA do Rio de Janeiro, bem como a experiência portuguesa da RVCC e a VAE da França, por possibilitarem ao estudante, em vários turnos e horários, momentos de aprendizagem e testagem, oportunidades de certificação da escolarização, considerando a importância dos saberes advindos da experiência do trabalho, o que pode possibilitar, conforme a obra de Peter Jarvis (2015), um processo de disjunção da aprendizagem dos jovens, dos adultos e também dos idosos.

\section{Notas}

1 Agradeço imensamente a leitura atenta, as correções da escrita e as contribuições ao texto da professora, Mestre em Educação, Margarete Maria Chiapinotto Noro.

2 Martins (1989, p. 98) sugere um caminho de compreensão das relações sociais sem o reducionismo, que o autor considera implícito no entendimento de classe social: “[...] a categoria de subalterno é certamente mais intensa e mais expressiva que a simples categoria de trabalhador. O legado da tradição gramsciana, que nos vem por meio dessa noção, prefigura a diversidade das situações de subalternidade, a sua riqueza histórica, cultural e política. Induz-nos a entender a diversificação de concepções, motivos, pontos-de-vista, esperanças, no interior das diferentes classes e grupos subalternos”.

3 As obras de Brunel (2004), Carrano (2007) e Dayrell (2007) são algumas das produções acadêmicas que refletem sobre o fenômeno da juvenilização da EJA e o quanto a escola precisa compreender sobre as culturas juvenis que advêm da periferia, da exclusão, da ancestralidade indígena e africana negadas pela tradição europeia branca da escola.

4 Na gestão governamental iniciada no ano de 2019, o Ministério do Trabalho e Emprego foi transformado em Secretaria do Trabalho, compondo então uma pasta do Ministério da Economia.

5 O termo supletivo é mencionado na I Campanha de Educação de Adolescentes e Adultos (CEAA), coordenada por Lourenço Filho em 1947. O lançamento da campanha foi no I Congresso de Educação de Adultos, "com a meta de abrir dez mil classes de ensino supletivo em cidades, vilas e povoados para adolescentes e adultos analfabetos...” (Soares, 1996, p. 1). A distribuição dos recursos nacionais e a abertura de classes de ensino supletivo possuíam como referência os municípios, a fim de possibilitar ao interior, não apenas às áreas urbanizadas, o ensino de jovens e adultos. Foram organizadas, dessa forma, um número significativo de classes de alfabetização. Beisiegel (1974) fez um estudo específico sobre as repercussões da Campanha de 1947, no estado de São Paulo; Soares (1996) no estado de Minas Gerais.

6 Catelli Jr, Serrao e Gisi (2013) analisam o processo de implementação do ENCCEJA.

7 A pesquisa de campo, considerando suas etapas de produção, sistematização e análise dos dados no período de agosto de 2016 a dezembro de 2018 contou com a atuação dos bolsistas de Iniciação Científica: Douglas Grando de Souza (então acadêmico da Licenciatura de Física), Amanda Santiago da Silva (acadêmica da Licenciatura em Pedagogia) e Bárbara Bohn (acadêmica da Licenciatura em Pedagogia).

8 Conforme consulta ao site do Inep, o ENCCEJA, tanto para a certificação do nível fundamental quanto para o nível médio, será em 04 de agosto de 2019, e as inscrições de 20 a 31 de maio. Disponível em: <http://portal.inep.gov.br/artigo/-/asset_publisher/B4AQV9zFY7Bv/content/id/6389965>. Acesso em: 07 mar. 2019

9 Mesmo constando na LDB a referência à Educação de Jovens e Adultos (EJA), ainda ocorre a utilização do termo supletivo, carregado da memória de aligeiramento e processo compensatório, não do entendimento do direito à Educação desses jovens e adultos trabalhadores.

10 Disponível em: <http://www.forumeja.org.br/>. Acesso em: 24 abr. 2017. 
11 O estudo de Serrao (2014) analisa o ENEM e o ENCCEJA como certificadores.

12 In Fórum EJA Paraná. Disponível em: <http://forumeja.org.br/pr/node/252>. Acesso em: 23 maio 2017.

13 A proposta pedagógica intitulada “Trajetórias Criativas” é voltada para os estudantes em idade de 15 a 17 anos que ainda não concluíram o Ensino Fundamental. As políticas vinculadas à Educação Integral do então Ministério da Educação nos anos de 2011 a 2014 estimularam sua formulação junto ao Colégio de Aplicação da UFRGS, Secretaria do Estado do Rio Grande do Sul e escolas estaduais parceiras. A sistematização da proposta pedagógica está publicada nos Cadernos Trajetórias Criativas: <https://www.ufrgs.br/trajetoriascriativas/publicacoes/>. Acesso em: 22 jun. 2016.

14 Os NEEJAS possuem regimento escolar padrão de funcionamento aprovado pelo parecer 765/2015 do Conselho Estadual de Educação, o qual define suas normas de funcionamento pedagógicas e de infraestrutura.

15 A institucionalização do CERTIFIC é posterior à publicação do artigo de Moraes e Neto (2005) sobre a necessidade de formulação de uma política pública de certificação profissional e, de certa forma, recupera as ponderações dos autores sobre a articulação dos dois Ministérios: Trabalho e Educação, composição de um conselho gestor tripartite da política: representação dos trabalhadores, representação dos empresários e representação do governo. No entanto, o alcance do CERTIFIC, instituído especialmente na rede federal de Educação Profissional, Científica e Tecnológica, foi muito abaixo diante da demanda dos trabalhadores brasileiros por certificação.

16 Santos (2010, p. 122) define a terceira lição do Programa de Educação Profissional Integrada à Educação Básica na Modalidade Educação de Jovens e Adultos (PROEJA) como: a existência de um currículo integrado ou fagocitado.

17 No artigo de Moraes e Neto (2005), são descritos os sistemas da França e da Itália de reconhecimento de saberes e competências dos trabalhadores, sendo na França recorrente a elevação de escolaridade. Tais dispositivos de reconhecimento, baseados em provas, aferição por meio de entrevistas, demonstrações práticas, foi resultado de negociações ocorridas desde os anos 1970 entre sindicatos de trabalhadores e empresários, sendo compostas comissões de acompanhamento da implementação de processos de reconhecimento de saberes e competências nas diversas categorias profissionais.

18 No artigo de Moraes e Neto (2005), há esta defesa: que no mesmo local, no mesmo escritório, ao qual o estudante trabalhador se dirige, seja possível aferir a elevação de escolaridade e a qualificação profissional.

19 A obra “Teorias Contemporâneas da Aprendizagem” organizada por Illeris (2013) traz um conjunto de autores os quais tem dedicado suas reflexões sobre os modos, as motivações das aprendizagens dos adultos, entre eles Peter Jarvis aqui citado. Paulo Freire é referência, especialmente para a construção das concepções de aprendizagem transformadora de Jack Mezirow.

\section{Referências}

BALANDIER, Georges. A Desordem: elogio do movimento. Rio de Janeiro: Bertrand Brasil, 1997.

BARDIN, Laurence. Análise de Conteúdo. Tradução: Reto LA, Pinheiro A. São Paulo: Edições 70, 2011.

BAUMAN, Zygmunt. Vidas Desperdiçadas. Rio de Janeiro: Jorge Zahar, 2005.

BEISIEGEL, Celso de Rui. Estado e educação popular. São Paulo: Pioneira, 1974.

BRASIL. Lei n. 9.394, de 20 de dezembro de 1996. Estabelece as Diretrizes e Bases da Educação Nacional. Diário Oficial [da República Federativa do Brasil], Brasília, DF, 1996.

BRASIL. Lei 11.892/2008 (Lei Ordinária) 29/12/2008. Institui a Rede Federal de Educação Profissional, Científica e Tecnológica, cria os Institutos Federais de Educação, Ciência e Tecnologia, e dá outras providências. Diário Oficial da União, Brasília, 2008.

BRASIL. Emenda Constitucional 59, dá nova redação aos incisos I e VII do art. 208, de forma a prever a obrigatoriedade do ensino de quatro a dezessete anos e ampliar a abrangência dos programas suplementares para todas as etapas da educação básica, e dá nova redação ao § $4^{\circ}$ do art. 211 e ao $\S 3^{\circ}$ do art. 212 e ao caput do art. 214, com a inserção neste dispositivo de inciso VI. Diário Oficial da União, Brasília, 2009 a.

BRASIL. Ministério da Educação. Portaria Interministerial n. 1.082 de 20 de novembro de 2009. Brasília, 2009b. 
BRASIL. Lei n. 13.005, de 25 de junho de 2014. Aprova o Plano Nacional de Educação - PNE e dá outras providências. Diário Oficial da União, Brasília, 2014.

BRASIL, Emenda Constitucional n. 95, de 15 de dezembro de 2016. Altera o Ato das Disposições Constitucionais Transitórias, para instituir o Novo Regime Fiscal, e dá outras providências. Diário Oficial da União, Brasília, 2016.

BRASIL. Lei No 13.415 de 16 de fevereiro de 2017. Altera as Leis nos 9.394, de 20 de dezembro de 1996, que estabelece as diretrizes e bases da educação nacional, e 11.494, de 20 de junho 2007, que regulamenta o Fundo de Manutenção e Desenvolvimento da Educação Básica e de Valorização dos Profissionais da Educação, a Consolidação das Leis do Trabalho - CLT, aprovada pelo Decreto-Lei no 5.452, de 1o de maio de 1943, e o Decreto-Lei no 236, de 28 de fevereiro de 1967; revoga a Lei no 11.161, de 5 de agosto de 2005; e institui a Política de Fomento à Implementação de Escolas de Ensino Médio em Tempo Integral. Diário Oficial da União, Brasília, 2017.

BRASIL. Lei No 13.632, de 6 de março de 2018. Altera a Lei no 9.394, de 20 de dezembro de 1996 (Lei de Diretrizes e Bases da Educação Nacional), para dispor sobre educação e aprendizagem ao longo da vida. Diário Oficial da União, Brasília, 2018a.

BRASIL. Decreto 9.432, de 29 de junho de 2018. Regulamenta a Política Nacional de Avaliação e Exames da Educação Básica. Diário Oficial da União, Brasília, 2018b.

BRUNEL, Carmen. Jovens cada vez mais Jovens na Educação De Jovens e Adultos. Porto Alegre: Editora Mediação, 2004.

CARRANO, Paulo. Educação de Jovens e Adultos e Juventude: o desafio de compreender os sentidos da presença dos jovens na escola da 'segunda chance'. 2007. Disponível em: $<$ http://www.emdialogo.uff.br/sites/default/files/educacao_de_jovens_e_adultos_e_juventude__carrano.pdf 2007>. Acesso em 07 mar. 2019.

CATELLI Jr., Roberto; GISI, Bruna; SERRAO, Luís Felipe Soares. Encceja: cenário de disputas na EJA. Revista Brasileira de Estudos Pedagógicos (online), Brasília, v. 94, n. 238, p. 721-744, set./dez. 2013.

CATELLI Jr., Roberto; SERRAO, Luis Felipe Soares. O ENCCEJA no Cenário das Políticas de Educação de Jovens e Adultos no Brasil. In: CATELLI Jr., Roberto; HADDAD, Sérgio; RIBEIRO, Vera Masagão (Org.). A EJA em xeque: desafios das políticas de educação de jovens e adultos no século XXI. São Paulo: Global, 2014.

CAVACO, Carmen. Adultos Pouco Escolarizados. Diversidade e Interdependência de Lógicas de Formação. Tese (Doutoramento em Ciências da Educação) - Universidade de Lisboa, Lisboa, 2008. Disponível em: $<$ http://repositorio.ul.pt/bitstream/10451/972/1/17505_ulsd_re286_TD_Carmen_Cavaco3.pdf >. Acesso em: 07 mar. 2019.

CEED-RS. Conselho Estadual de Educação Rio Grande do Sul. Parecer 765/2015. Aprova o Regimento Escolar Padrão para o Ensino Fundamental e para o Ensino Médio dos Núcleos de Educação de Jovens e Adultos - NEEJAs para os alunos maiores de 18 anos. Porto Alegre. 2015a.

CEED-RS. Conselho Estadual de Educação Rio Grande do Sul. Parecer CEED no 765/2015. Regulamenta os Núcleos de Educação de Jovens e Adultos do Rio Grande do Sul. Porto Alegre, 14 de outubro de 2015. Porto Alegre, 2015b.

CREJA. Centro Municipal de Referência de Educação de Jovens e Adultos. Projeto Político Pedagógico 20172021. Rio de Janeiro, 2017. Texto digitado.

DAYRELL, Juarez. A Escola “Faz” As Juventudes? Reflexões Em Torno Da Socialização Juvenil. Educação \& Sociedade, Campinas, v. 28, n. 100, Especial, p. 1105-1128, out. 2007.

ELIAS, Norbert; SCOTSON, John L. Os Estabelecidos e os Outsiders. Rio de Janeiro: Jorge Zahar, 2000.

FREIRE, Paulo. Pedagogia da Esperança. 17. ed. São Paulo: Paz e Terra, 2011. 
IBGE. Instituto Brasileiro de Geografia e Estatística. Censo Demográfico 2010. Pessoas de 10 anos ou mais de idade, por nível de instrução, segundo a situação do domicílio e os grupos de idade - Rio Grande do Sul - 2010. Rio de Janeiro: IBGE, 2011. Disponível em: <ftp://ftp.ibge.gov.br/Censos/Censo_ Demografico_2010/Educacao_e_Deslocamento/xls/rio_grande_do_sul_xls.zip>. Acesso em: 01 maio 2017.

IFSC. Instituto Federal de Santa Catarina. Notícias, Florianópolis, 24 de março de 2011 https://www.ifsc.edu.br/conteudo-aberto/-/asset_publisher/1UWKZAkiOauK/content/25-03-experienciado-certific-do-campus-florianopolis-continente-e-destaque-internacion-2/30681. Acesso em 26 de maio de 2014.

ILLERIS, Knud (Org.). Teorias Contemporâneas da Aprendizagem. Porto Alegre: Penso, 2013.

JARVIS, Peter. Aprendizagem Humana: Implícita e Explícita. Educação \& Realidade, Porto Alegre, v. 40, n. 3, p. 809-825, jul./set. 2015.

JESUS, Carolina Maria de. Quarto de Despejo: diário de uma favelada. São Paulo: Ática, 2014.

KUSCH, Rodolfo. America Profunda. 3.ed. Buenos Aires: Editorial Bonum, 1986.

MARTINS, José de Souza. Caminhada no Chão da Noite. São Paulo: Hucitec, 1989.

MORAES, Carmen Sylvia Vidigal; NETO, Sebastião Lopes. Educação, formação profissional e certificação de conhecimentos: considerações sobre uma política pública de certificação profissional. Educação \& Sociedade, Campinas, v. 26, n. 93, p. 1435-1469, 2005.

MORAIS, Anabela R. A.; OLIVEIRA, Albertina. Percepções sobre os "novos" processos de RVCC na Educação de Adultos: evolução ou involução metodológica. In: ALCOFORADO, Luís et al. Diálogos Freireanos: educação e formação de jovens e adultos em Portugal e no Brasil. Recife: Editora UFPE; Coimbra: Imprensa da Universidade de Coimbra, 2018.

PAIVA, Jane. Dez Anos de Proeja. Porto Alegre: UFRGS, 2017. (comunicação oral).

RIO GRANDE DO SUL. Resolução 343 de 11 de abril de 2018. Consolida normas relativas à oferta da Educação de Jovens e Adultos (EJA) no Sistema Estadual de Ensino. Diário Oficial do Estado do Rio Grande do Sul, Porto Alegre, 13 abr. 2018. p. 130-136.

SANTOS, Simone Valdete dos. Sete lições sobre o Proeja. In: MOLL, Jaqueline (Org.). Educação profissional e tecnológica no Brasil contemporâneo: desafios, tensões e possibilidades. Porto Alegre: Artmed, 2010. p. $120-130$.

SERRAO, Luis Felipe Soares. Exames para certificação de conclusão de escolaridade: os casos do ENCCEJA e do ENEM. 2014. Dissertação (Mestrado em Educação) - Programa de Pós-Graduação em Educação, Universidade de São Paulo, São Paulo, 2014.

SOARES, Leôncio José Gomes Soares. A Educação de jovens e adultos - momentos históricos e desafios atuais. Presença Pedagógica, Belo Horizonte, v. 2, n. 11, p. 26-35, set./out. 1996.

SZYMANSKI, Heloísa (Org.). A Entrevista na Pesquisa em Educação: a prática reflexiva. 4. ed. Brasília: Liber Livro, 2011.

\section{Correspondência}

Simone Valdete dos Santos: Professora da Universidade Federal do Rio Grande do Sul.

E-mail: simone.valdete@ufrgs.br

Texto publicado em Currículo sem Fronteiras com autorização da autora 